\title{
DEVELOPMENT OF A CERAMIC FOAM FILTER FOR FILTERING MOLTEN ALUMINUM ALLOY IN CASTING PROCESSES
}

\author{
Ehsaan-Reza.Bagherian", Mohd Khairol Ariffin ${ }^{2}$, Shamsuddin Sulaiman ${ }^{3}$ \\ ${ }^{1}$ Department of Mechanical and Manufacturing Engineering Universiti Putra Malaysia 43400 UPM Serdang, \\ Malaysia \\ ${ }^{2}$ Department of Mechanical and Manufacturing Engineering Universiti Putra Malaysia 43400 UPM Serdang, \\ Malaysia \\ ${ }^{3}$ Department of Mechanical and Manufacturing Engineering Universiti Putra Malaysia 43400 UPM Serdang, \\ Malaysia
}

\begin{abstract}
Currently, liquid metal filtration in casting process is a familiar refining technology for casting process. This technique be able to exist removed the inclusions inside the melts and subsequently improves the mechanical properties of the product. Furthermore this will also improved the surface finish and tightness of cast product. This significantly reduced the rework cost. The present research was done to fabricate an improved ceramic foam filter for use in filtering aluminum base alloys. It was an objective of the present work to provide a ceramic foam filter characterized by cost of raw materials. Then experimental tests were carried out to the filters to measure permeability properties before pouring process. After pouring process, thermal shock properties, obtain from pouring liquid aluminum when filter was placed in the gating system to ensure that the filters could withstand temperatures of aluminum alloys. Then filter was cut into several sections to measure the macro and microstructure of the filter and ensure that impurity particles captured by a filter. Further experiments were also done to investigate the efficiency of produced ceramic foam filter on quality of cast products. The result obtained in this investigation, the mechanical properties for aluminum LM6 alloy sand casting increased when ceramic foam filter was inserted into the gating system. A produced filter by using new materials is economical to produce. Further more, the analysis data shows present innovation filter which can be made in any shape and size, has excellent thermal shock resistance, and acceptable permeability properties.
\end{abstract}

Keywords: Ceramic Foam Filter; Polymeric Sponge Method; Aluminum Casting; Metal Filtration; New Additives Raw Materials.

\section{INTRODUCTION}

The usage of Ceramic Foam Filter (CFF) grew continuously in metal casting process, for the reason that of the value added is greater than the cost of filter application and cost for purchasing filter. Whereas 20 years ago filter were used only in emergency cases but at present filter can be considered an integral part of casting (Sadon et al., 2001). This is due to the advantages of the metal filtration which can be divided into three categories such as benefit to the foundry, benefits to the foundry`s customer and benefit to the final cast product (Schmahl and Aubrey, 1993b). Since 1976-2007 several efforts had been done to fabricate various ceramic foam filters in foundry industry include U.S. Patent 3947363 (Ceramic foam filter 1976), U.S. Patent 4343704 (Ceramic foam filter 1982), and U.S. Patent 4391918 (Ceramic foam filter and aqueous slurry for making same 1983) and U.S. Patent WO/2007/120483(Low expansion corrosion resistant ceramic foam filters for molten aluminum filtration 2007). Although all of the filters which have been fabricated in these patents have achieved acceptable ideal properties (high thermal shock resistance, adequate strength and low density), but none of them have been able to reach an acceptable price. Therefore the present research has been done to fabricate ceramic foam filter for filtration of aluminum alloy with new cheaper additives materials and improve a ceramic foam filter for using in filtration of molten metal, especially aluminium based alloys.

\section{FABRICATION OF CERAMIC FOAM FILTER}

The experimental procedures for fabrication of ceramic foam filter are explained from section 2.1 to 2.6. The present ceramic foam filters are produced by immersing the polymeric sponge with an aqueous ceramic slurry, then burn out to leave a porous ceramic.

\subsection{Material Description for Preparation Ceramic Foam Filter}

The following sections explain the essential properties of refractories materials and bond for preparation of ceramic foam filter (Corns, 1991).

- Refractory aggregate materials and type of bond must not decompose or melt over the temperature range of filter would be used. 
- Filter materials must be able to withstand the initial priming head.

- Thermal shock resistance to molten metal without creeping, melting, breaking down or filter fragment.

- Corrosion resistance to slag and inclusion in molten metal.

- Mechanical, physical properties.

- $\quad$ High temperature properties.

Alumina, Silicon carbide, Zirconia, Chromia and Magnesia are raw materials, which contain the above properties and are used to produce filters (Schmahl and Aubrey, 1993a). Alumina is the most significant material composition of ceramic slurry for aluminium alloy. Silicon carbide, Zirconia, Chromia and Magnesia are the most important parts of material compositions for filtration of cast iron, steel alloy, copper alloys and magnesium alloy, respectively (Kinikoglu, 1998).

In this present study, alumina, carbon, Bentonite and silicon dioxide selected as a refractory materials and sodium silicate selected as a binder.

- The principal component of the ceramic foam material of the present innovation is $\mathrm{Al}_{2} \mathrm{O}_{3}$. In accordance with the present innovation, the $\mathrm{Al}_{2} \mathrm{O}_{3}$ is present in amounts of from 50 to $70 \mathrm{wt} \%$. Because $\mathrm{Al}_{2} \mathrm{O}_{3}$ is desirable for use as a ceramic foam filter for filtering of aluminium alloy because alumina has essential strength to stand up to chemical attack by molten aluminium.

- Carbon, Bentonite and Silicon carbide in an amount from 20 to $30 \mathrm{wt} \%$ were other additives refractories materials, because of their high thermal shock conductivities are used in the filter composition.

- Bentonite is natural clay composed of aluminum and silicates, usually with some magnesium and iron. Bentonite has been found to be one of an important additive. The advantages of Bentonite are described in U.S. Pat. No. 3947363, which are provides binding function and produces glassy phases upon firing yielding strength in the final product. In addition, the Bentonite provides control of uniformity of retention of the slurry in the organic foam material.

- In order to decrease the cost of raw materials, sand from beach, which has a Silicon Dioxide in an amount from 10 to $20 \mathrm{wt} \%$ has been found to be a particularly important additive to the slurry composition of the present innovation.

- The binder material provides sufficient strength to hold the mixture together for formation of the final product. The binder of the present innovation is sodium silicate.

- Generally from 10 to $40 \%$ binder and water are present in the slurry. The water content simply obtains suitable fluidity to immerse the polymeric foam into the aqueous slurry and coat the sponge. As described in U.S. Pat. Nos. 3947363, it is known the water component is used in order to aid in controlling viscosity of aqueous slurry which can impregnate the foam material with the slurry (Pryor and Thomas, 1976).

\subsection{Sponge Selection}

Providing reticulated organic polymer foam is the second step in fabrication of ceramic filter after preparation of raw materials (Jerry and Aubrey, 1989). Because shape and pore size of the sponge must be exactly the same as final filter, selecting suitable polymeric foam plays an important role for filter making. Basically there are two types of sponge for preparation of ceramic foam filters: (a) expendable polystyrene foam and (b) polyurethane foam, which have essential properties.

(a) Expendable polystyrene foam is a thermoplastic insulating material, which is produced from petroleum (Monroe, 1992). Although this foam has larger surface area for deep bed filtration in comparison with the Polyurethane foam, high costs of production and heavy weight of the filters, which are produced with this foam, are main obstacles for this foam to be used in industries (Taslicukur et al., 2007).

(b) Polyurethane foam is flexible and porous organic polymer foam. This type of foam is suitable for fabrication of ceramic foam filters (Monroe, 1992). There are three main categories to produce Polyurethane foam (Hebner, 1995): (a) conventional block process using slab machine, (b) max foam process by using max foam machine and (c) VPF process by using variable pressure force machine (Joseph, 1990).This foam has excellent tensile strength, wet heat resistance, thermal resistance, density, oxidation resistance, low gas permeation properties, low temperatures characteristics, excellent waterproofness and impact resilience (Goods and Neuschwanger, 1999). According to the above properties, this foam is suitable to be used in various applications (Brockmeyer, 1982) such as molten metal filtration and air filtration, heating, ventilating, air conditioning, automobiles, humidifiers, vacuum cleaners, power brake air filter, blood filters and oil/water separators (Joseph, 1990) .

Typical polymeric sponges are available from 3.94 - 39.4 inch in width and $0.394-3.94$ inch in thickness and $10-70$ porosity per inch. In present innovation a polyurethane foam material was provided having a thickness of 5.58 inch and containing 20 pores per linear inch. This polyurethane foam was cut manually by scissor as desire shapes such as rectangular, square and circle.

\subsection{Preparation the Slurry}

After the sponge is selected, the slurry must be prepared by mixing the ceramic powder and additives in water. The various aqueous slurry compositions for preparation of ceramic foam filter used in filtration of molten aluminum alloys have been studied by Pryor (Pryor and Thomas, 1976) Brockmeyer (Brockmeyer, 1982) Jerry (Jerry, 1983) and Feng (Feng, 2007) from 1976 to 2007 and their finding is summarized in Table 1. Also during the same period, Foseco Metallurgical Inc performed SIVEX ceramic foam filter such as Sivex 200S (Foseco Metallurgical Inc, 1990), SivexS (Foseco Metallurgical Inc, 1997) and Sivex FC (Foseco Metallurgical Inc, 2007) that is presented in Table 2 and materials used in present research is shown in Table 3. 
Table 1: Materials composition used for ceramic foam filter preparation on U.S Patents

\begin{tabular}{|c|c|c|}
\hline U.S Patent no & Base material & Additives \\
\hline $\begin{array}{l}3947363 \\
(1976)\end{array}$ & 40 to $95 \mathrm{wt} \% \mathrm{Al}_{2} \mathrm{O}_{3}$ & $\begin{array}{l}1 \text { to } 25 \mathrm{wt} \% \mathrm{Cr}_{2} \mathrm{O}_{3} \\
0.1 \text { to } 12 \mathrm{wt} \% \text { bentonite } \\
2.5 \text { to } 25 \mathrm{wt} \% \text { of an air setting agent which is substantially } \\
\text { nonreactive to the molten metal }\end{array}$ \\
\hline $\begin{array}{l}4343704 \\
(1982)\end{array}$ & 50 to $70 \mathrm{wt} \% \mathrm{Al}_{2} \mathrm{O}_{3}$ & $\begin{array}{l}2 \text { to } 10 \mathrm{wt} \% \text { micron sized reactive alumina } \\
1 \text { to } 5 \mathrm{wt} \% \text { montmorillonite } \\
1 \text { to } 10 \mathrm{wt} \% \text { ceramic fibers } \\
5 \text { to } 25 \mathrm{wt} \% \text { of a ceramic binder or air setting agent }\end{array}$ \\
\hline $\begin{array}{l}4391918 \\
(1983)\end{array}$ & 55 to $70 \mathrm{wt} \% \mathrm{Al}_{2} \mathrm{O}_{3}$ & $\begin{array}{l}2 \text { to } 10 \% \text { micron-sized reactive alumina } \\
1 \text { to } 5 \mathrm{wt} \% \text { montmorillonite } \\
1 \text { to } 10 \mathrm{wt} \% \text { ceramic fiber }\end{array}$ \\
\hline $\begin{array}{l}\text { WO/2007/120483 } \\
(2007)\end{array}$ & $20-70$ wt $\% \mathrm{Al}_{2} \mathrm{O}_{3}$ & $\begin{array}{l}20 \text { to } 60 \mathrm{wt} \% \mathrm{SiO}_{2} \\
0 \text { to } 10 \mathrm{wt} \% \mathrm{CaO} \\
0 \text { to } 10 \mathrm{wt} \% \mathrm{MgO} \\
2 \text { to } 20 \mathrm{wt} \% \mathrm{~B}_{2} \mathrm{O}_{3}\end{array}$ \\
\hline
\end{tabular}

Table 2: Materials composition used for ceramic foam filter preparation on Foseco Metallurgical Inc MSDS (Materials Safety Data Sheet)

\begin{tabular}{|l|l|l|}
\hline SIVEX no & Base material & Additives \\
\hline $\begin{array}{l}\text { SIVEX 200S } \\
(1990)\end{array}$ & zircon>40 wt $\%$ & alumina $>40 \mathrm{wt} \%+$ high temperature binder \\
\hline $\begin{array}{l}\text { SIVEX S } \\
(1997)\end{array}$ & zircon>80 wt $\%$ & high temperature binder \\
\hline $\begin{array}{l}\text { SIVEX FC } \\
(2007)\end{array}$ & $\mathrm{Al}_{2} \mathrm{O}_{3}>75 \mathrm{wt} \%$ & $\begin{array}{l}\text { Mixture of silica crystalline and quartz around } 1 \text { to } 5 \mathrm{wt} \%\left(\mathrm{SiO}_{2} \sim\right. \\
1-5 \mathrm{wt} \%)+ \text { high temperature binder }\end{array}$ \\
\hline
\end{tabular}

In present innovation (Table 3), An aqueous slurry for use in preparing low cost and high thermal shock resistant ceramic foam having the following composition: 50 to $70 \mathrm{wt} \% \mathrm{Al}_{2} \mathrm{O}_{3}, 20$ to $30 \mathrm{wt} \%$ Carbon, Bentonite and Silicon carbide, 10 to $20 \mathrm{wt} \%$ Sand form beach (Silicon dioxide). Slurry also containing from 10 to $40 \%$ water and sodium silicate binder. The material composition is under patent pending and waiting for the approval.

Table 3: Materials composition used for ceramic foam filter preparation in present research

\begin{tabular}{|l|l|l|}
\hline Present research & Base material & Additives \\
\hline $2007-2009$ & 50 to $70 \mathrm{wt} \%$ & $\begin{array}{l}20 \text { to } 30 \mathrm{wt} \% \text { Carbon, Bentonite and Silicon carbide } 10 \text { to } 20 \\
\mathrm{wt} \% \text { Sand form beach (Silicon dioxide) } \\
\mathrm{Al}_{2} \mathrm{O}_{3}\end{array}$ \\
\hline
\end{tabular}

\subsection{Immersing the Sponge and Removing Excess}

\section{Slurry}

Going forward through this step, two important factors should be considered: (a) the sponge should be compressed before immersing into the slurry to remove air and (b) Impregnation of foam with the aqueous slurry should be done by simply immersing the foam in the slurry in a short period of time, which is sufficient to ensure complete coating of foam. Subsequently, impregnated foam should be compressed to remove between 25 to $75 \%$ of the slurry from the sponge (Kinikoglu, 1998). In present experiment, impregnated foam is compressed manually.

In present innovation the aqueous slurry which is described above is prepared and the polyurethane foam is then impregnated. The resultant immersed foam was manually removed from the excessive slurry. This process is done by using the fork to ensure that impregnated material is expelling from $25-75 \%$ of the slurry. The compression is released so that the materials remains coated with the slurry. Although the balance is uniformly distributed throughout the foam material, but preferably so that some pores are blocked in a uniformly distributed manner to increase the tortuosity. Therefore the range of 25-75 is not exact and this process should be done to ensure complete coating of foam (Jerry, 1983)

\subsection{Drying and Baking Ceramic Slurry}

Drying and baking of the impregnated foam are the next stages. Drying and baking of the ceramic material after impregnated foam with the aqueous ceramic slurry is performed in an oven at a temperature between $100^{\circ \mathrm{C}}$ and $300^{\circ \mathrm{C}}$ with ramp rate of 12 centigrade per minute for 15 minutes. The impregnated foam is also can be dried by other technique such as air drying but air drying as described in U.S. Pat. Nos. 4885263 (Jerry and Aubrey, 1989) may be achieved in from 8 to 24 hours. However, as described in 
U.S. Pat. No. WO/2007/120483 (Feng, 2007), short durations of drying and baking of ceramic slurry are desirable for high manufacturing rates and process economics.

\subsection{Burning out the Sponge}

The dried material is then heated to first burn out the flexible organic foam and then sinter the ceramic coating. Therefore firing of the ceramic material is the next stage to heat the materials to a temperature of from $300^{\circ \mathrm{C}}$ to $800{ }^{\circ \mathrm{C}}$ with ramp rate of $8^{\circ} \mathrm{C} / \mathrm{min}$ and hold within said temperature range for 45 minutes in order to sinter the ceramic. As described in U.S. Pat. Nos. WO/2007/120483, Lower temperatures and shorter durations improve manufacturing economics. However, sufficient time and temperature must be provided to achieve the desired strength and corrosion resistance properties of the final product (Feng, 2007). Table 4 shows the program used in this work to performed drying and baking of ceramic slurry and firing foam by high chamber furnace.
Table 4: Program used to performed drying and baking of ceramic slurry and firing foam

\begin{tabular}{|l|l|}
\hline Stage & Enter \\
\hline 1 PAR To $\mathrm{r}_{1}$ & $12^{\circ} \mathrm{C} /$ min \\
\hline 2 PAR To $\mathrm{L}_{1}$ & $300^{\circ} \mathrm{C}$ \\
\hline 3 PAR To $\mathrm{d}_{1}$ & 15 minute \\
\hline 4 PAR To $\mathrm{r}_{2}$ & $8^{\circ} \mathrm{C} /$ min \\
\hline 5 PAR To $\mathrm{L}_{2}$ & $800^{\circ} \mathrm{C}$ \\
\hline 6 PAR To $\mathrm{d}_{2}$ & 45 minute \\
\hline
\end{tabular}

$$
\begin{aligned}
& \text { Where PAR = Parameter button } \\
& \mathrm{r}_{1}=\text { Ramp rate one in Deg }{ }^{\circ} \mathrm{C} / \text { min } \\
& \mathrm{L}_{1}=\text { temperature level one in Deg }(\mathrm{C}) \\
& \mathrm{d}_{1}=\text { Hold time one in minute } \\
& \mathrm{r}_{2}=\text { Ramp rate two in Deg }{ }^{\circ} C_{\text {min }} \\
& \mathrm{L}_{2}=\text { temperature level two in Deg }(\mathrm{C}) \\
& \mathrm{d}_{2}=\text { Hold time two in minute }
\end{aligned}
$$

The twenty complete filters are produced with various shapes and are shown in Figure 1.

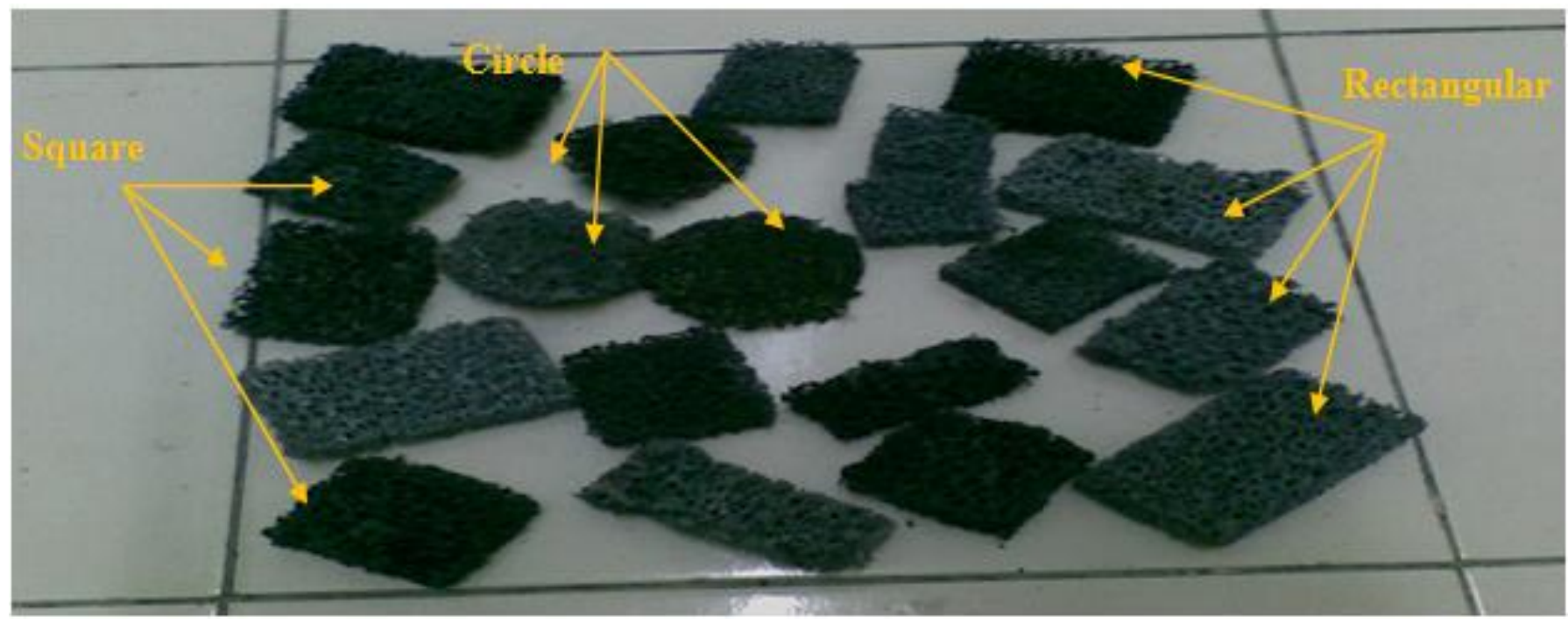

Fig.1. Various type of ceramic foam filter produced

\section{EXPERIMENTAL RESULTS}

In this paper the ceramic form filter is measure in term of flow modification, weight and volume test, surface inspection, macro and micro structure.

\subsection{Permeability Measurement}

In filtration applications, the main criteria to evaluate the ceramic foam filters are permeability and mechanical strength. [6] V.R. Salvini, M.D.M. Innocentini and V.C. Pandolfelli, Cerâmica 46 (2000), pp. 97-103.Ideally, the ceramic filter should be able to remove the maximum of impurities with minimum resistance to the flow of fluids. This characteristic can be obtained by increasing the volume or increasing size of pores of polymeric foams. However, these two options usually compromise the mechanical strength of the structure (Sousa and Rambo, 2008)

There are two tests available to evidence of ceramic foam filter's permeability and turbulence: (a) computer simulation and (b) physical test.

- First method is computer simulation by using computer-aided engineering software. Basically the software can simulate flow modification capabilities of ceramic foam filter (Millin, 1999)Moreover simulation program can predict fluid flow characteristics such as flow velocity and pressure, also it is possible to analyse and determine relative 
levels of turbulence as the metal flow through the gating and into the casting cavity (Qutten, 1996)

- The second category is physical testing such as air flow test and water modelling test. Water modelling test is done by using a water flow testing machine (Alquist, 2003) or visual evidence by holding a filter in the path of water stream and comparing the appearance of the stream as it enter and exit the filter (Wenping, 2006)

In present paper, imported and produced ceramic foam filter hold on stream of tap water, then permeability of filter and turbulence from stream of water considered through following stages: (1) the empty container is placed on sink, (2) hold the filter on the stream of tap water for 5 seconds, (3) read the water that spilled over the container, (4) for each case of produced and imported filter, 3 specimens tested and all steps are repeated. Figure 2 shows, both produced and imported ceramic foam filter, can reduce turbulence from stream of water. Apart of this, analyze data for permeability measurement is shown in Table 5 and it is plotted in Figure 3. It is indicated that, the highest weight (mean value) is $276.66(\mathrm{ml})$ for produced filter samples and the lowest is $263.33(\mathrm{ml})$ for imported filtered samples. This value shows, permeability of imported filter is $4.818 \%$ higher in comparison with produced filtered samples. Permeability is a very important characterization of filter products. It is used to measure the velocity rate at where liquid flowing through a porous medium. But permeability of filters is normally characterized by some parameters such as bulk density of raw materials which are used for fabricating of filters and particle size, distribution, In present study, both of imported and produced filters have the same porosity distribution about 20 PPI (porosity per inch) but as mentioned in item 4.3 bulk densities of imported filters were more than produced filters. Therefore according to Table 5 permeability of imported filter is $4.818 \%$ higher in comparison with produced filtered samples.

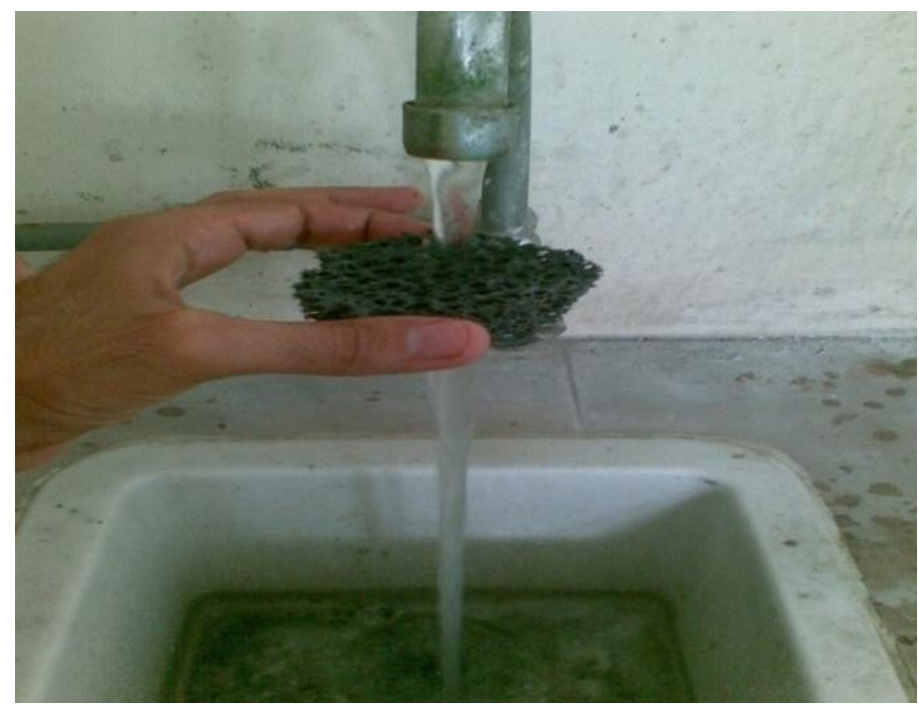

(a) Produced ceramic foam filter

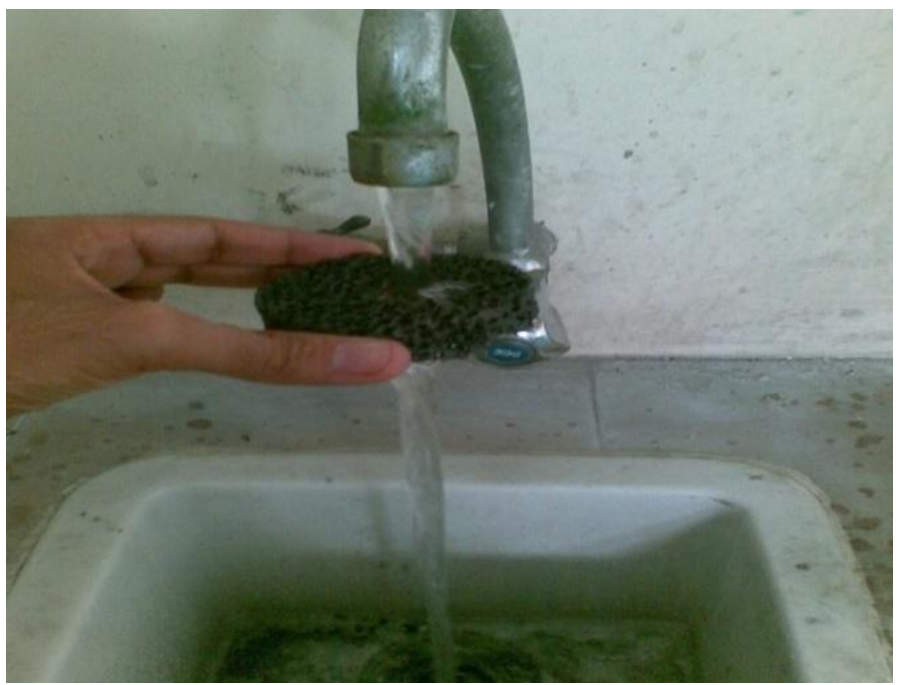

(b) Imported ceramic foam filter

Fig.2. Flow modification test by water modelling 
Table 5.Comparison permeability of produced and imported filters

\begin{tabular}{|c|c|c|c|c|}
\hline Sample & Sample 1 & Sample 2 & Sample 3 & $\begin{array}{c}\text { Average Volume } \\
(\mathbf{m l})\end{array}$ \\
\hline Produced filter & 270 & 285 & 275 & 276.66 \\
\hline Imported filter & 255 & 270 & 265 & 263.33 \\
\hline
\end{tabular}

\section{Volume}

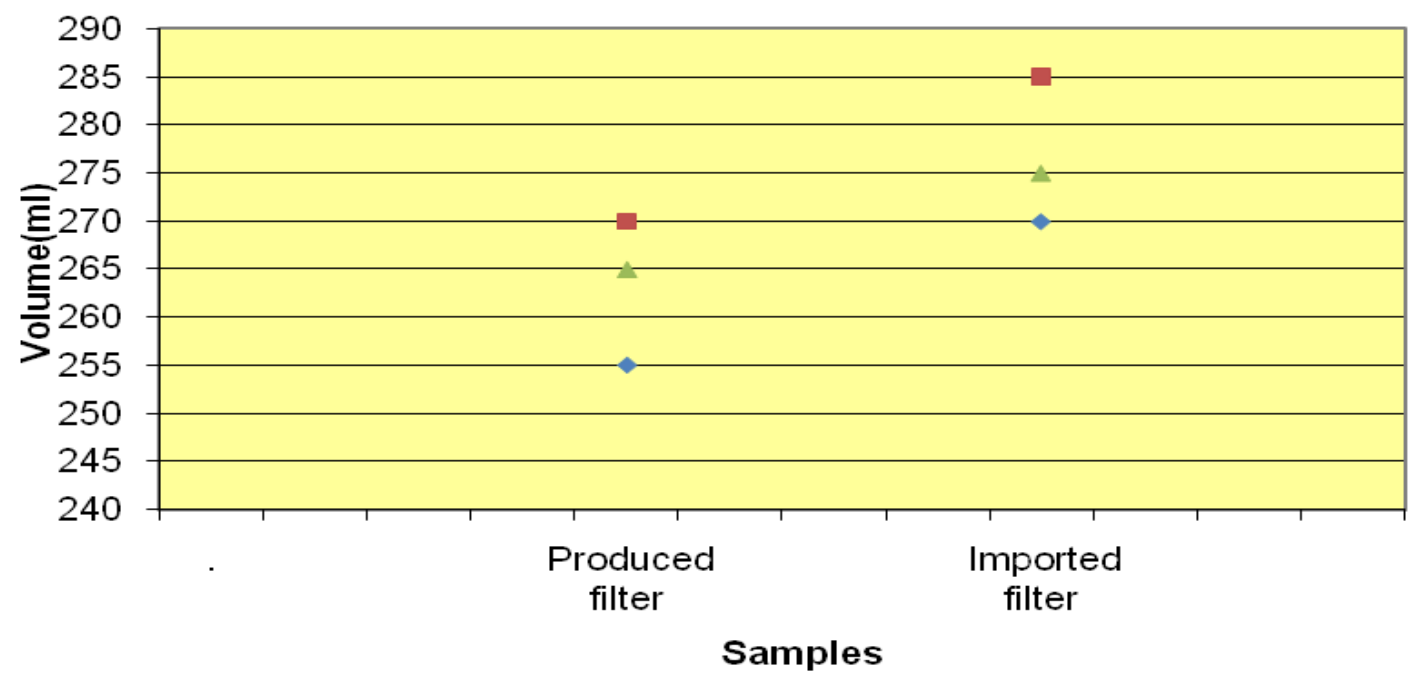

Fig.3. Flow modification test by water modelling

\subsection{Weight of Metal Containing Filter and No-}

\section{Filter Measurement}

To considering weight and volume of metal contain filter, the authors have selected two patterns for $\mathrm{CO}_{2}$ mold applying which are shown in Figure 4(a) and Figure 5(a). Silica sand as the base material and liquid sodium silicate was selected for making $\mathrm{CO}_{2}$ mold. The mold is subjected to $\mathrm{CO}_{2}$ gassing for hardening purpose. After this the sand is rammed manually by using a sand rammer over the sides of the pattern. Then sand mixtures are drilled to supply $\mathrm{CO}_{2}$. After gassing with carbon dioxide, the pattern is detached from the sand. For case of filtered casting, cope and drag were assembled together by applying glue at the parting line to prevent flashing of molten metal during to pouring of molten metal into the mold cavity. (Figure 4(b) and Figure 5(b)). Then the melting of LM6 aluminum-silicon alloy was done by an induction furnace. To ensure the molten metal pass through the filter, the filter pouring temperature has to be increased around $50^{\circ} \mathrm{c}$ above the pouring temperature of non-filtered sand mould. The melt was transferred to a ladle, then into the sand mold while the cast had cooled down to room temperature, the sand mold was broken to acquire the cast. The cast was then cut by sawing machine to comparing in weight and volume of both imported and produced filters. Weight of metal contains both produced and imported filter are measured and compared with digital balance scale. For each cases of produced and imported filter, 3 samples are weighted and determinations are repeated. Moreover, these steps are repeated for non filtered sample in 2 times. The analyze data is shown in Table 6 and Figure 6. As indicated in this Table, it was found that the weight value decreased from $310.5(\mathrm{~g})$ in imported filter case and $307.01(\mathrm{~g})$ in produced filter case to $345.355(\mathrm{~g})$ in non-filtered sample. The total decrease of weight value for imported filter and produced filter is $10.09 \%$ and $11.10 \%$, respectively.

Table 6: Comparison data for weight of metal contains filter and no filter

\begin{tabular}{|l|l|l|l|l|}
\hline Weight of samples (g) & Sample 1 & Sample 2 & Sample 3 & Average \\
\hline Non-filtered & 340.48 & 350.23 & - & 345.355 \\
\hline Produced filter & 322.16 & 296.3 & 302.57 & 307.01 \\
\hline Imported filter & 290.43 & 314.44 & 326.63 & 310.5 \\
\hline
\end{tabular}




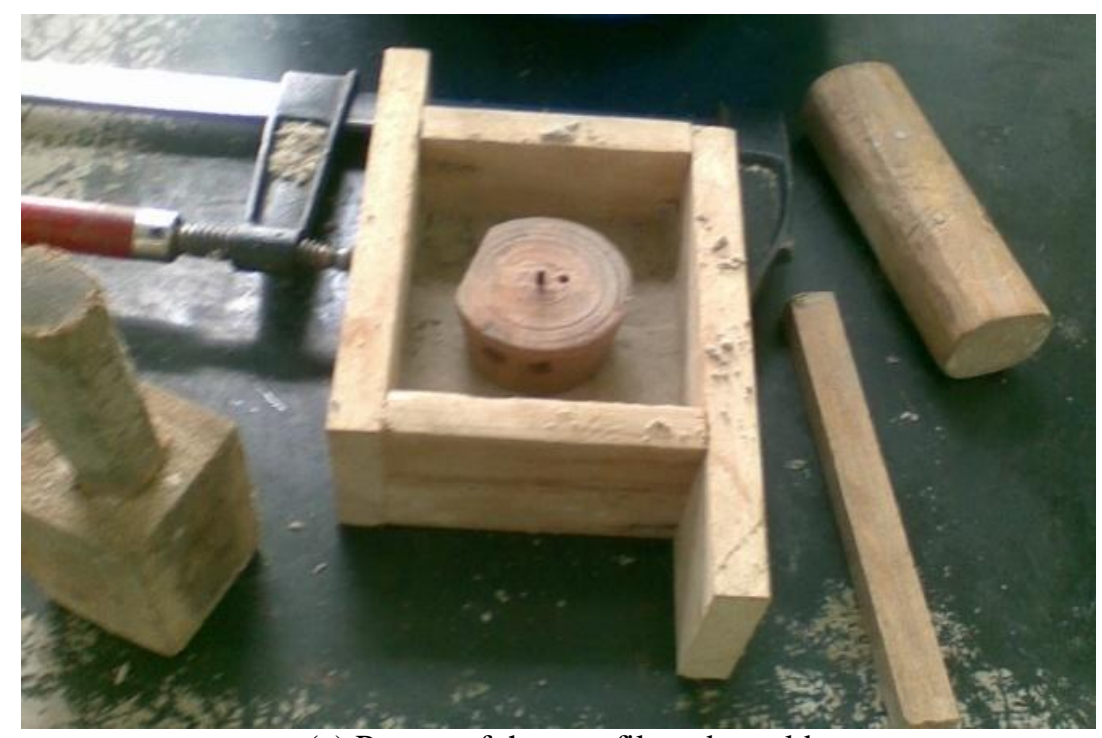

(a) Pattern of the non-filtered mould

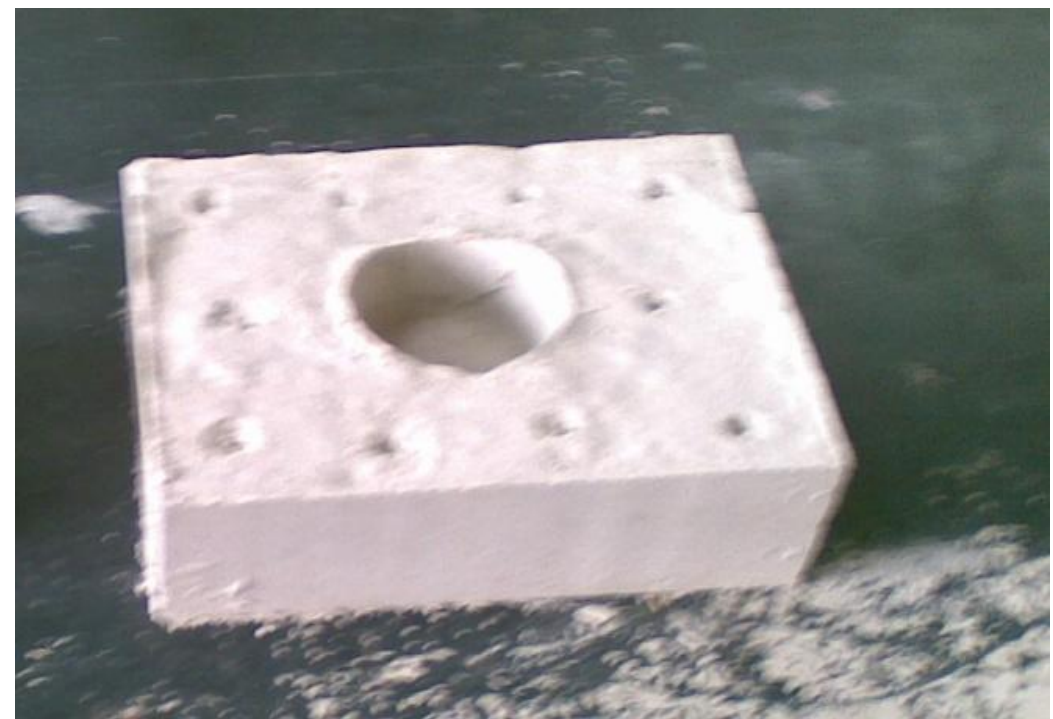

(b) Sand mould of non-filtered specimen

Fig.4. Pattern and Sand Mold without filter

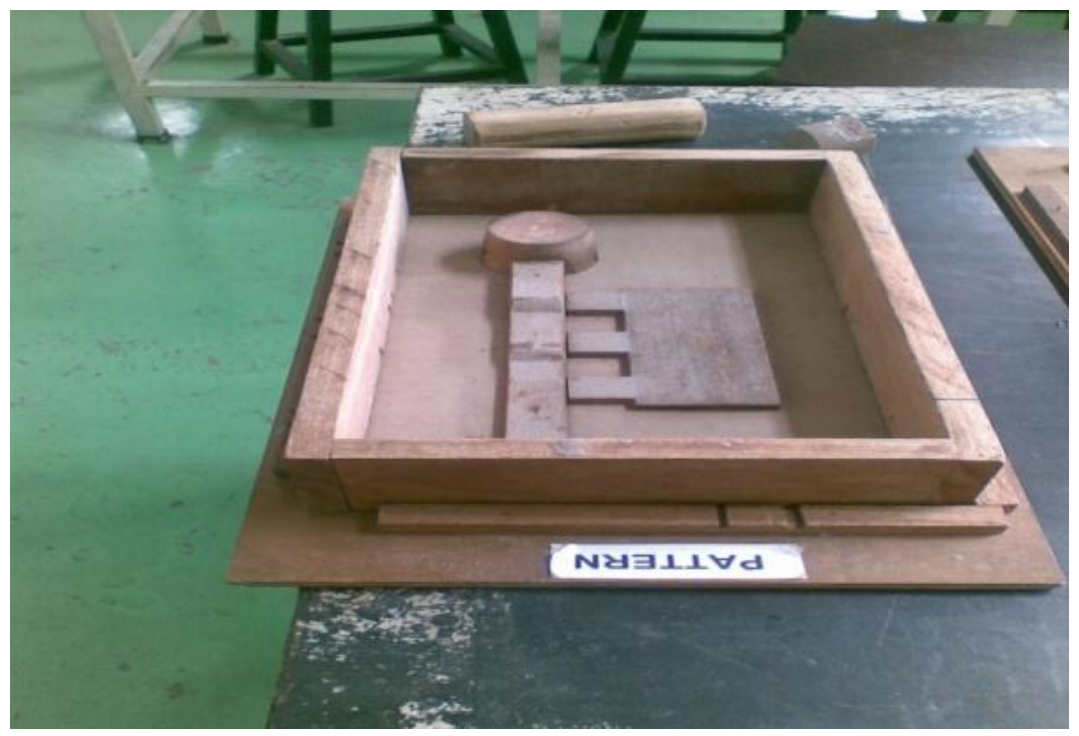

(a) Pattern of the filtered mould 


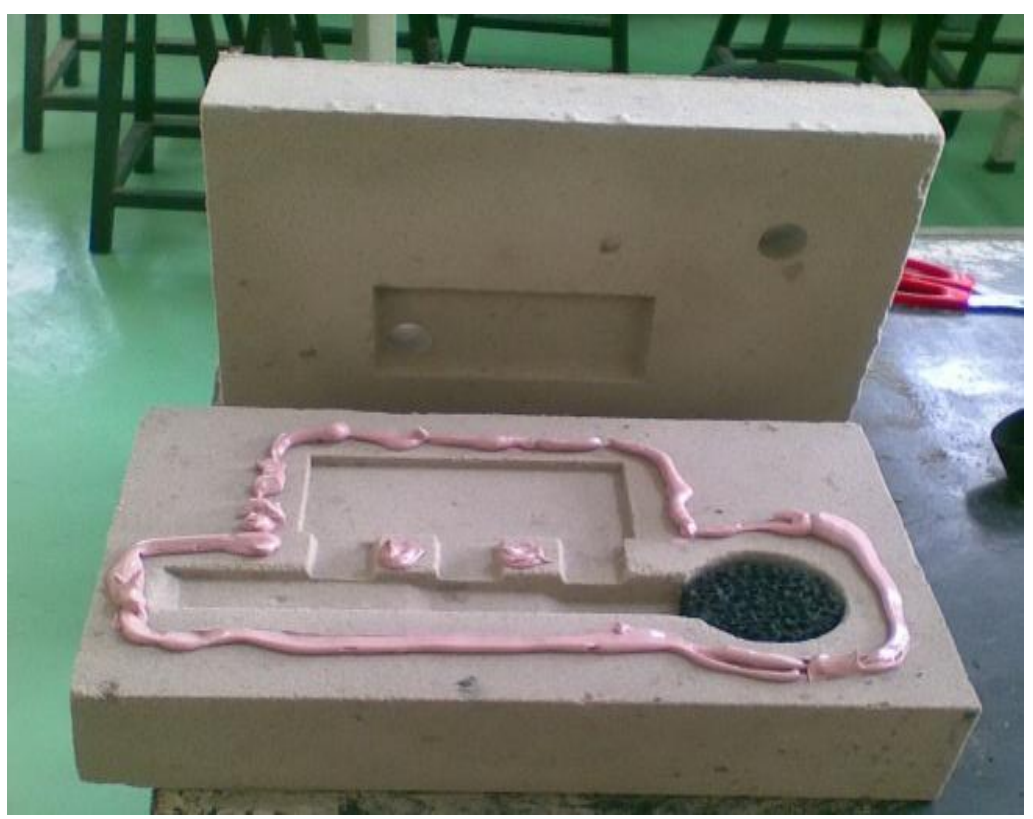

(b) Sand mould of filtered specimen

Fig.5. Pattern and Sand Mold with filter

\section{Weight}

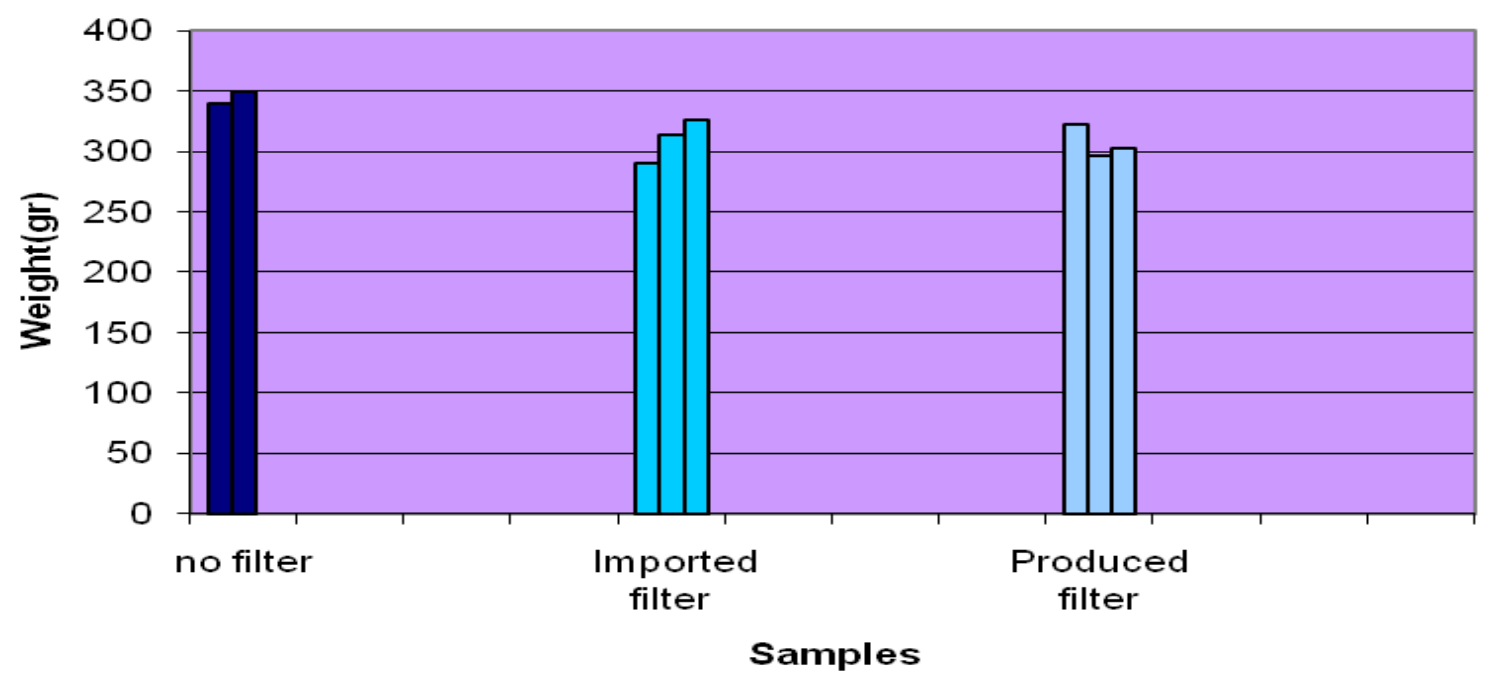

Fig.6. Comparison data for weight of metal contains filter and no filter

\subsection{Volume of Metal Containing Filter and No-}

\section{Filter Measurement}

To considering volume of metal contacting filter, firstly the empty container is placed on table. Then, sample put in the empty container. After that, another empty container filled with $600 \mathrm{ml}$ water. Then, the water inside the second container is poured into the first container which, sample is placed. Lastly water that spilled over the $600 \mathrm{ml}$ is measured. For each case of metal, which contain produced and imported filter, all steps are repeated by 3 times. But, the result for non filtered sample is obtained by 2 times repeated. The analyze data is shown in Table 7 and it is plotted in Figure 7. It is indicated that, the volume value has decreased from $688.33(\mathrm{ml})$ for imported filter and 688.66 $(\mathrm{ml})$ in produced filter case to $705(\mathrm{ml})$ in non-filtered sample. The total decrease of volume value for imported filter and produced filter is $2.36 \%$ and $2.31 \%$, respectively. Differences in weight and volume value of imported and produced filters which were compared with non-filtered samples are related to various bulk densities of raw materials which are used in fabrication of filters. 
Table 7.Comparison data for volume of metal contains filter and no filter

\begin{tabular}{|l|l|l|l|l|}
\hline Volume of samples (ml) & Sample 1 & Sample 2 & Sample 3 & Average \\
\hline Non-filtered & 700 & 710 & - & 705 \\
\hline Produced filter & 693 & 685 & 688 & 688.66 \\
\hline Imported filter & 680 & 690 & 695 & 688.33 \\
\hline
\end{tabular}

Volume

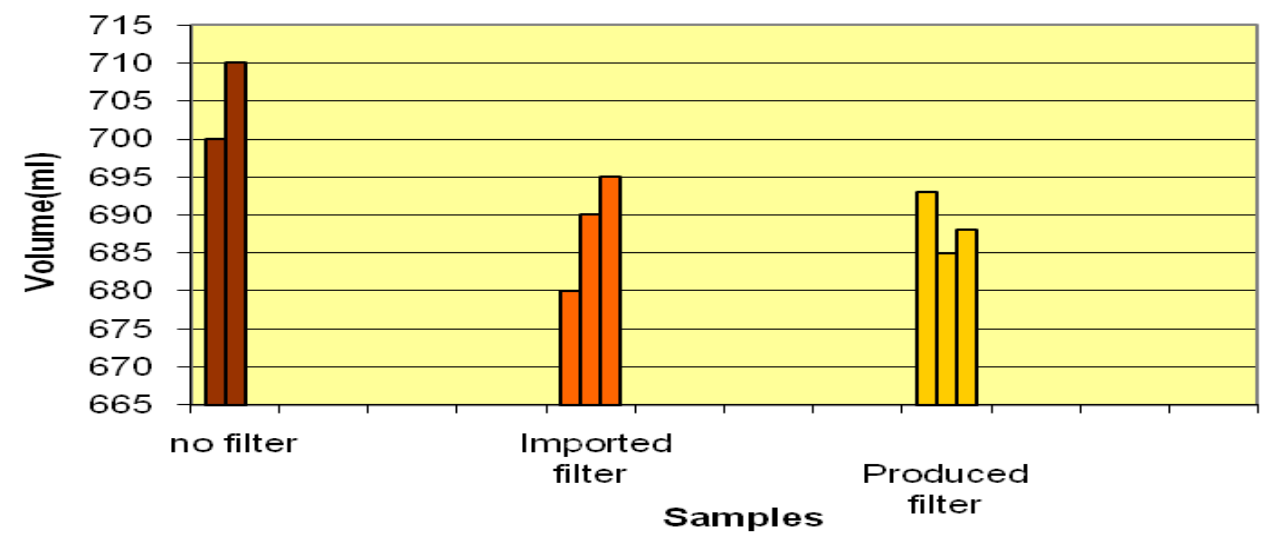

Fig.7. Comparison data for volume of metal contains filter and no filter

\subsection{Thermal Shock Inspection}

Thermal shock and erosion resistance of ceramic foam filter after pouring molten metal are the most important product attributes. These properties are evaluated by pouring molten metal and then surface inspection. In present work, surface of both produced and imported filter are visually inspected to detect any cracking or erosion in surface of filter after pouring molten metal and the result shown filters could withstand temperatures of aluminum melting point and they could be able to resist against chemical attack by molten aluminum alloys under typical use conditions. Also by visually inspection any fracture problem such as blocking, clogging, cracking, bending or erosion of filters after pouring molten aluminum into the mould cavity was not observed. (Figure 8)

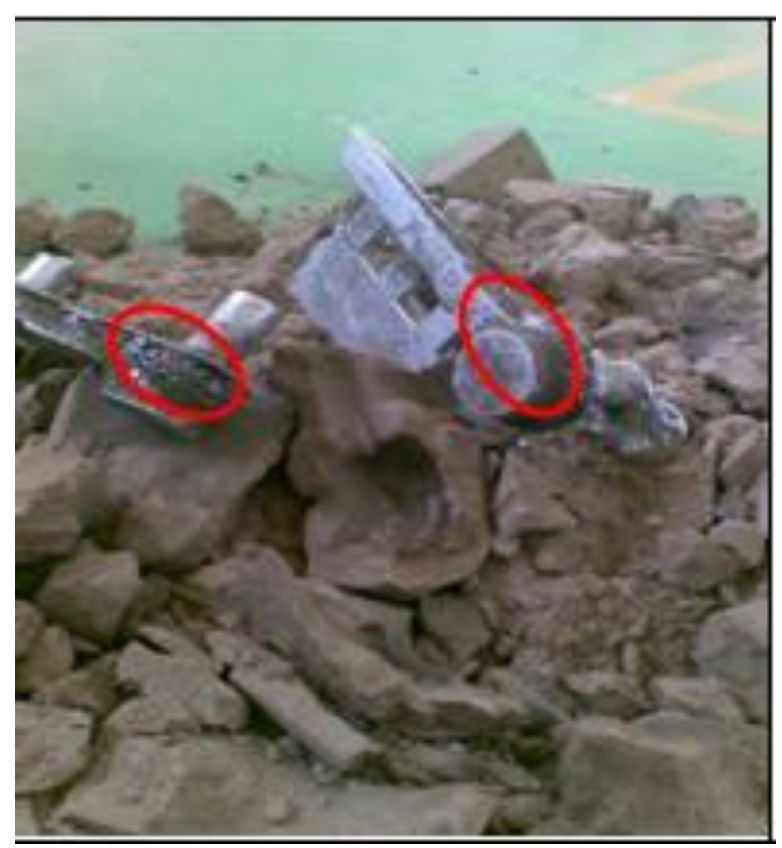

a) Filter after fabrication 


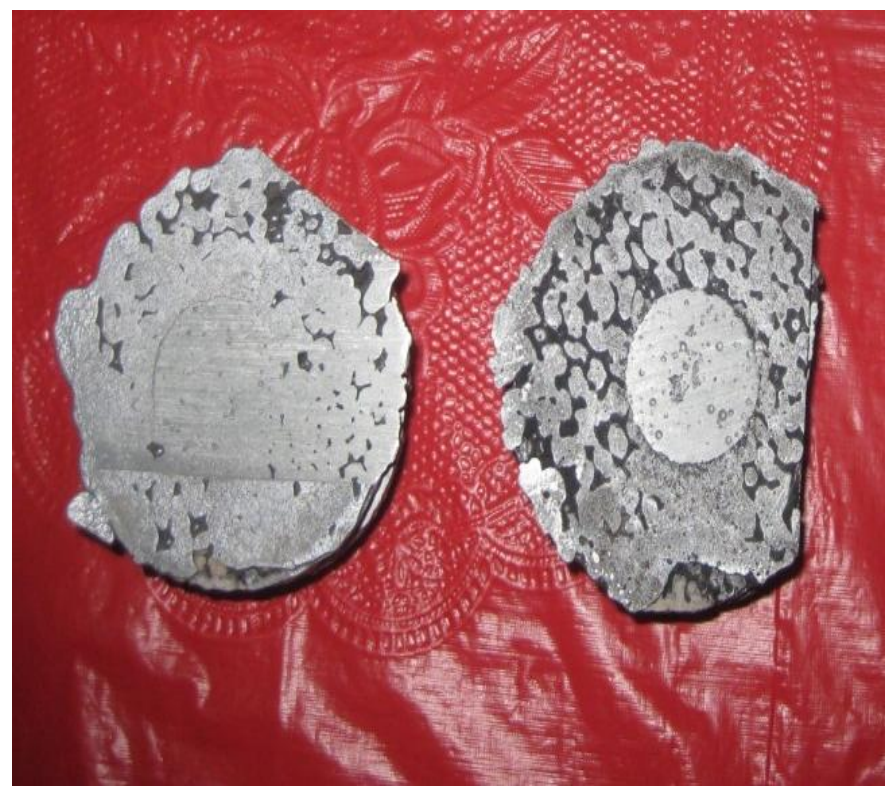

b) Macrostructure of produced filter

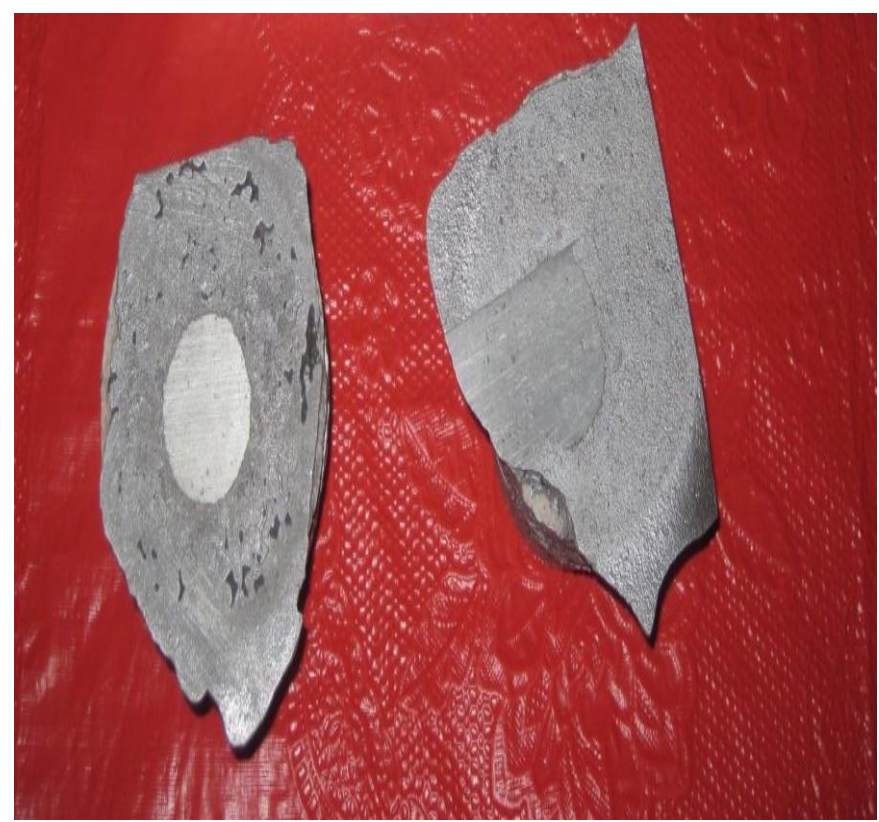

c) Macrostructure of imported filter

Fig.8. Surface inspection of imported and produced filters

\subsection{Macrostructure of Metal Containing Filter}

To ensure that impurity particles captured by a filter, metal containing filter was cut in several sections. Figure 9 (a) illustrates the view of macrostructure of metal containing produced filter and Figure 9 (b) shows macrostructure of imported filter. 


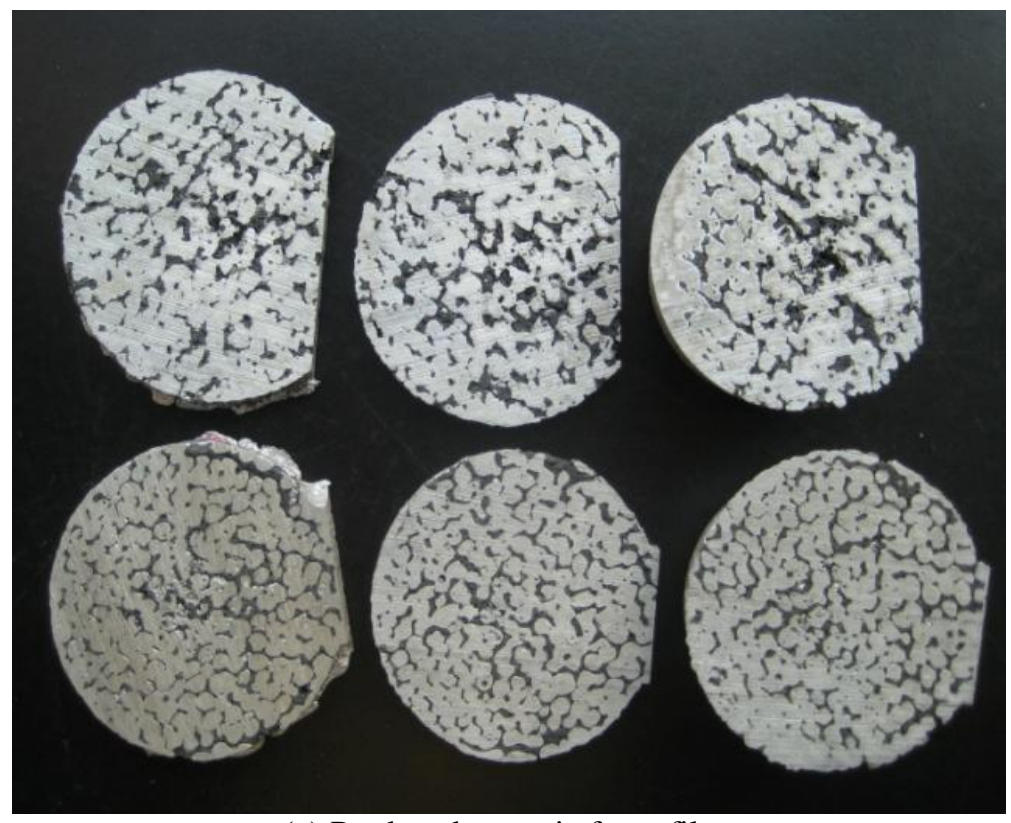

(a) Produced ceramic foam filter

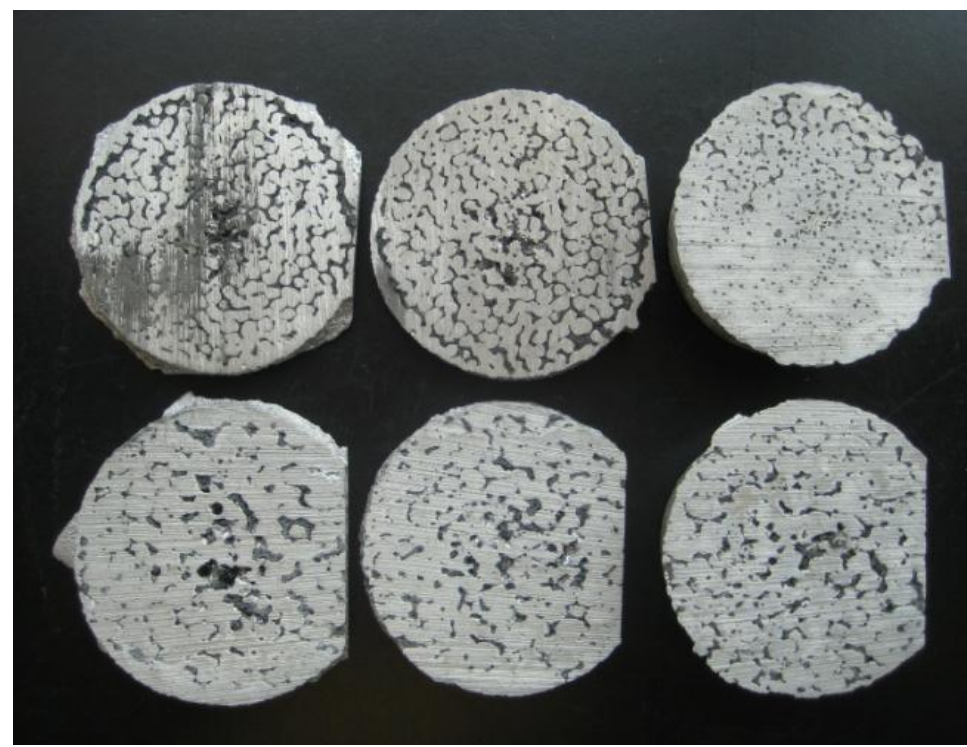

(b) Imported ceramic foam filter

Fig.9. Macrostructure of metal contains of imported and produced filters

\subsection{Microstructure of Metal Containing Filter}

Optical microscopic studies are conducted by using a metallurgical microscope to identify inclusion particle in each section of the metal containing filter, which was cut in previous step. This microscope facilitated with an image capturing facility to save the image into hard-drive as JPEG files. Figure 10 (a) to 10 (c) and Figure 10 (d) to 10 (f) are the optical micrographs (50 time zoom) of metal containing produced filter for all sections of sample one and sample two. The observed microstructure of three layers for sample one and two of imported filter (50 time zoom) are presented in Figure 11 (a) to 11 (c) and Figure 11 (d) to 11 (f). It is obviously clear that the impurity particles captured by a ceramic foam filter in each layer. The efficiency of ceramic foam filters in removing inclusions arising from the melt, alloying or mould processing can be seen in these Figures. These Figures show that there are also some small inclusions particle blocked at the first, middle and lower section of the filters. As indicated to these Figures, it was found that the particles blocked by web filters are combine cluster of inclusions, the same as those blocked on the top of the filter. These clusters of inclusions are not even distributed in the whole pore of the filter but only at special positions where the porosity between ceramic filter is narrow or may be special position of filters which are resistance to flow of melt. Because narrow distribution of ceramic foam filters makes it easy for these particles to be captures by the filter. 


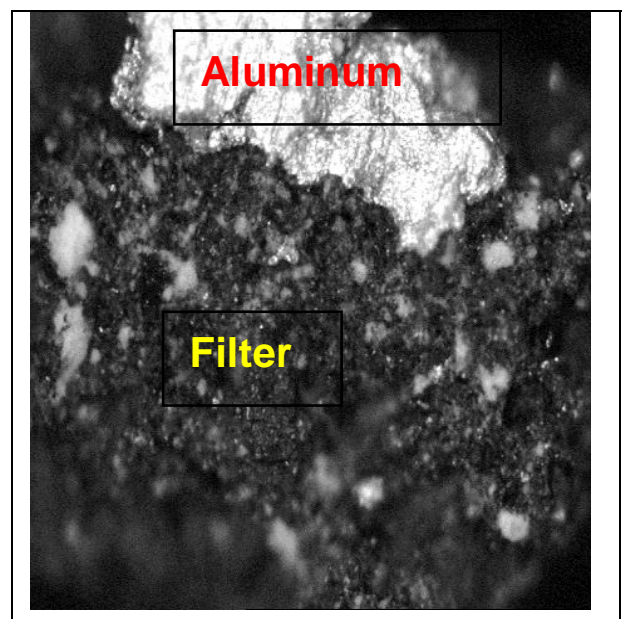

(a) First Layer

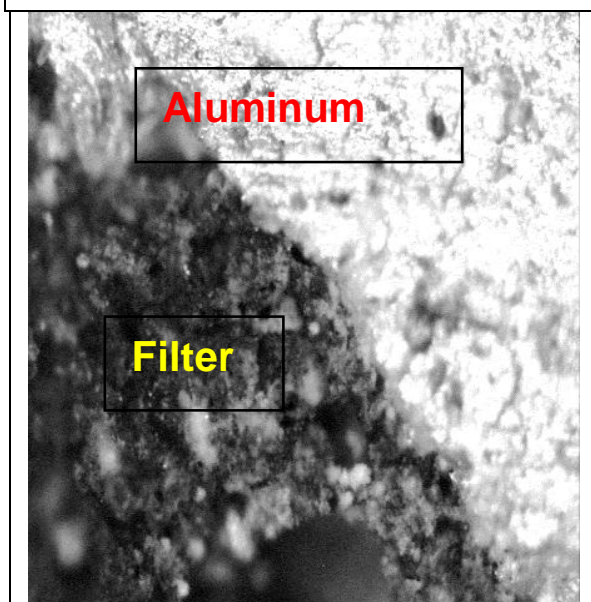

(d) First Layer

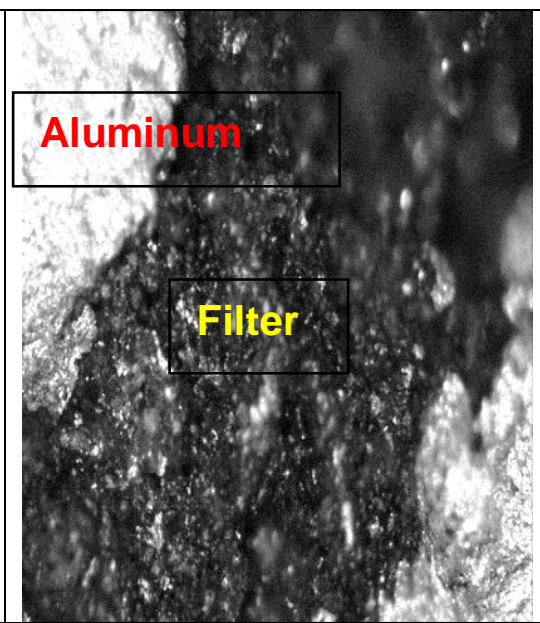

(b) Second Layer

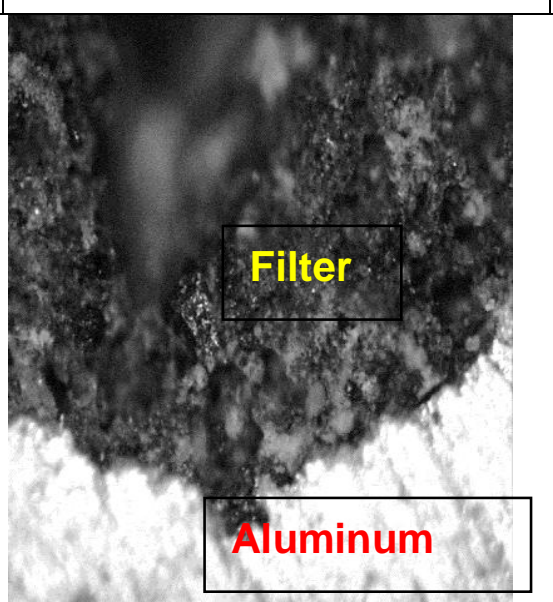

(e) Second Layer

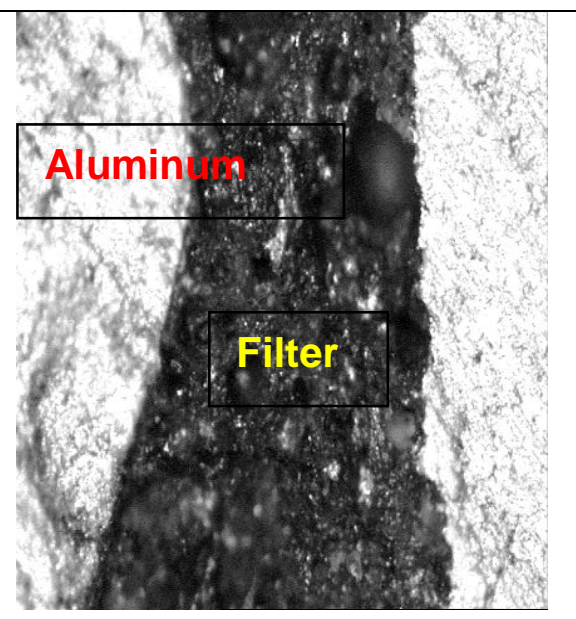

(c) Third Layer

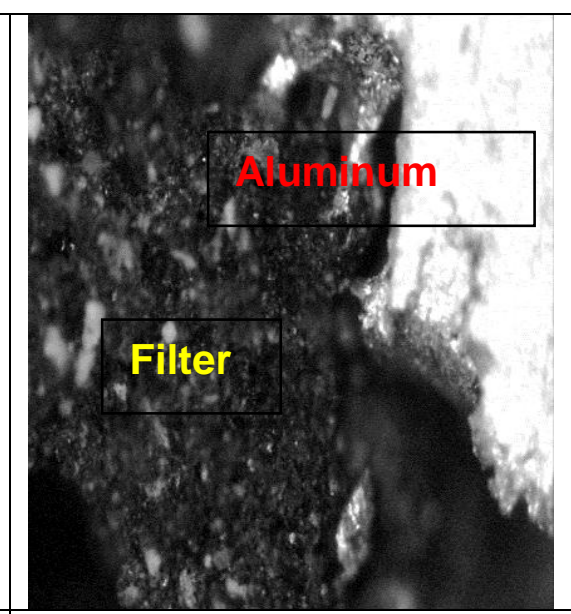

(f) Third Layer

Fig.10. Microstructure of metal contains produced filter

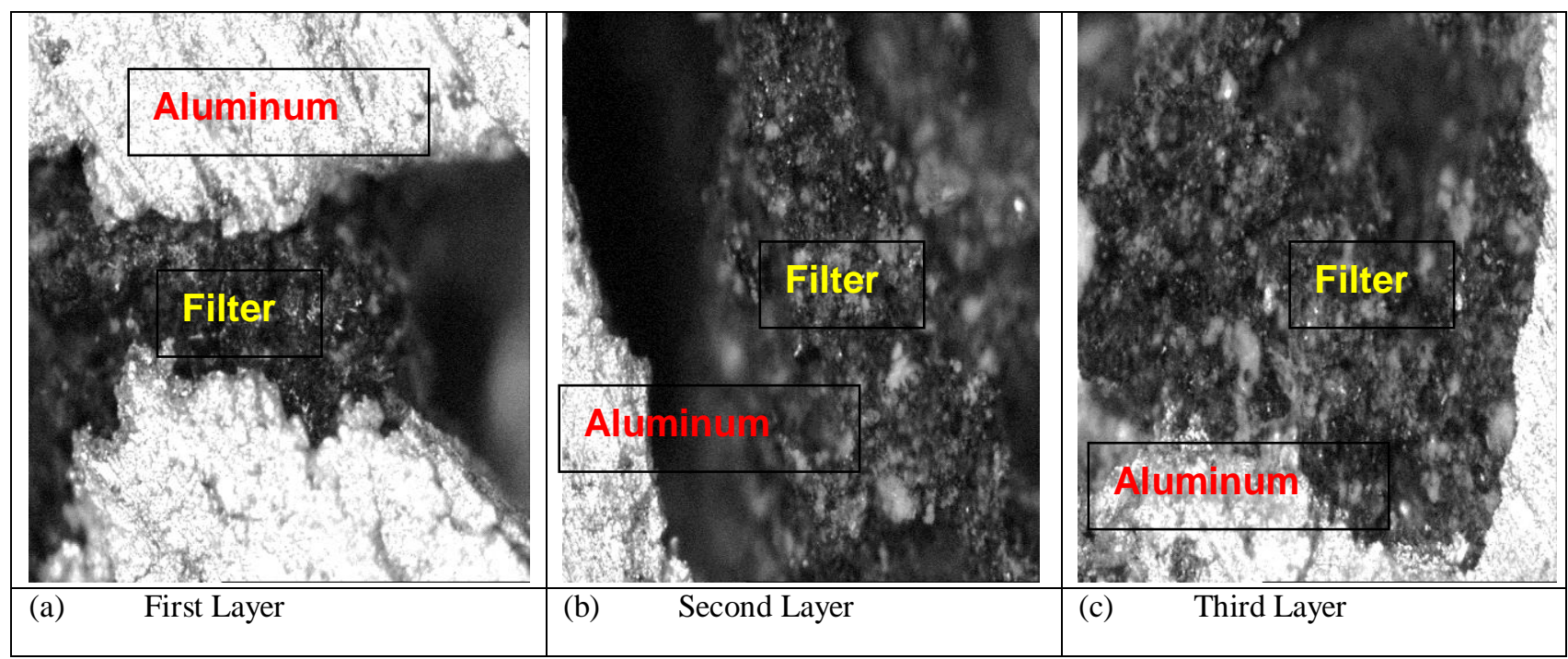




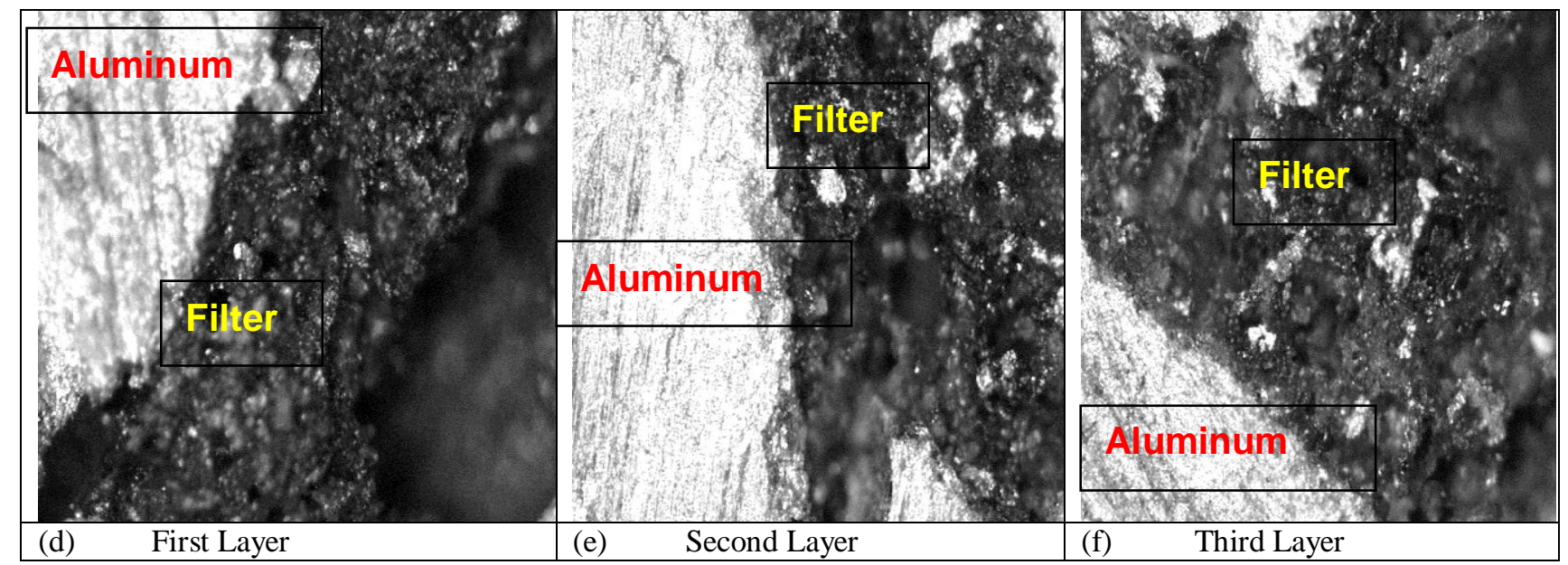

Fig.11. Microstructure of metal contains imported filter

\subsection{Brinell Hardness Testing}

In this experiment the hardness test was done according to the Brinell hardness testing technique. Brinell hardness testing is well known hardness test methods to determine the hardness of forging and casting parts, which is done by considering two elements such as force and diameter of the ball indenter. As for standard the test parameters for iron and steel castings the force is $3000 \mathrm{Kg}$ with a $10 \mathrm{~mm}$ diameter carbide ball, while for aluminum the force used is $500 \mathrm{Kg}$ with a 10 or $5 \mathrm{~mm}$ carbide ball for aluminum.

The acquire part from the sand mold was cut by saw machine to determine value of hardness of the filtered and non-filtered materials. As the next step the specimens milled and grinded. This process is done to ensure that the surface finished of the specimen is ready for the testing. Finally, the specimens are smooth by using ammonium oxide waterproof grinding paper prior to the actual Brinell testing. Following the ASTM E10-01 standard the test is required to press the indenter into the sample in $500 \mathrm{Kgf}$ or $4.903 \mathrm{KN}$ of load and $10 \mathrm{~mm}$ diameter of carbide ball for the testing. This test was done by using BRINELL WP300 UNIVERSAL TESTER $20 \mathrm{KN}$ machine. Then after fixing the specimen in table of Brinell hardness machine, the force is maintained for a specific dwell time for 15 seconds in each test, while the dwell time is complete, the indenter is removed and left a round indent in the sample, the round indent on the surface is measured by using two digits high accuracy digital caliper.

A total of five measurements are done for each of the test. The Brinell hardness number is calculated by using the following formula.

$$
\mathrm{HBW}=0.102 \times \frac{2 F}{\pi D\left(D-\sqrt{D^{2}}-d^{2}\right)}
$$

Table 8 shows five positions of the ball indention of produced, imported and non-filtered parts. The average ball indentions of 5 reading for produced filters are 3.364 which are compared to imported and non-filtered sample from 3.351 and 3.551 .

Also there are five measurements for each ball indention. The details of these results are tabulated in Tables 9. The total mean of the five positions and measurement is considered as the mean of the hardness reading. By comparing the un-filtered with the produced and imported filter samples, It was found that the hardness value have increased for the Brinell test in case of non-filtered specimens from $48.85 \mathrm{HBW}$ to $54.63 \mathrm{HBW}$ and $55.05 \mathrm{HBW}$ respectively in case of produced and imported samples test. The total improvement for the Brinell hardness test is increased by $10.58 \%$ in case of produced filter and $11.26 \%$ in imported filter samples. Figure 12 shows that every reading for the samples with filter are high compared to the all non-filter samples. However according to British standards 1490 LM6, Brinell hardness (mean value) of aluminum LM6 alloys are, between 50 to $55 \mathrm{BHW}$ and the results are still in range.

$\mathrm{D}=$ diameter of the ball, $\mathrm{mm}$

$\mathrm{F}=$ Test force, $\mathrm{N}$

$\mathrm{d}=$ mean diameter of the indentation, $\mathrm{mm}$ 
Table 8. Five positions of the ball indention of samples

\begin{tabular}{|c|c|c|c|c|c|c|}
\hline Sample & Reading & Ball indent & & & & \\
\hline \multirow{7}{*}{ 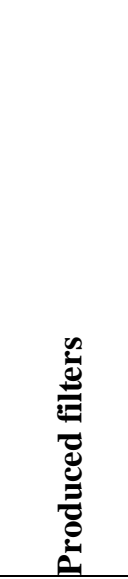 } & $\begin{array}{l}\text { Reading } \\
\text { number }\end{array}$ & specimen1 & specimen 2 & specimen 3 & specimen 4 & specimen 5 \\
\hline & 1 & 3.29 & 3.38 & 3.4 & 3.41 & 3.32 \\
\hline & 2 & 3.31 & 3.34 & 3.41 & 3.4 & 3.37 \\
\hline & 3 & 3.34 & 3.39 & 3.39 & 3.42 & 3.31 \\
\hline & 4 & 3.28 & 3.41 & 3.43 & 3.37 & 3.33 \\
\hline & 5 & 3.32 & 3.37 & 3.39 & 3.38 & 3.34 \\
\hline & Average & 3.308 & 3.378 & 3.404 & 3.396 & 3.334 \\
\hline \multirow{7}{*}{ 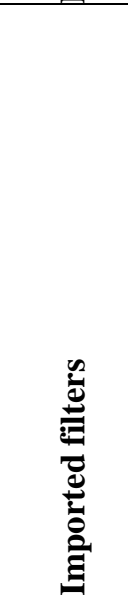 } & $\begin{array}{l}\text { Reading } \\
\text { number }\end{array}$ & specimen1 & specimen 2 & specimen 3 & specimen 4 & specimen 5 \\
\hline & 1 & 3.34 & 3.45 & 3.31 & 3.29 & 3.28 \\
\hline & 2 & 3.4 & 3.42 & 3.34 & 3.32 & 3.27 \\
\hline & 3 & 3.39 & 3.39 & 3.32 & 3.35 & 3.33 \\
\hline & 4 & 3.37 & 3.41 & 3.34 & 3.37 & 3.29 \\
\hline & 5 & 3.41 & 3.39 & 3.33 & 3.33 & 3.34 \\
\hline & Average & 3.382 & 3.412 & 3.328 & 3.332 & 3.302 \\
\hline \multirow{7}{*}{ 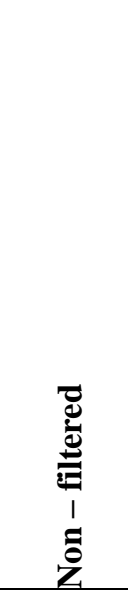 } & $\begin{array}{l}\text { Reading } \\
\text { number }\end{array}$ & specimen1 & specimen 2 & specimen 3 & specimen 4 & specimen 5 \\
\hline & 1 & 3.53 & 3.54 & 3.54 & 3.47 & 3.65 \\
\hline & 2 & 3.48 & 3.53 & 3.61 & 3.54 & 3.62 \\
\hline & 3 & 3.51 & 3.48 & 3.58 & 3.56 & 3.59 \\
\hline & 4 & 3.46 & 3.51 & 3.62 & 3.48 & 3.62 \\
\hline & 5 & 3.56 & 3.52 & 3.63 & 3.55 & 3.61 \\
\hline & Average & 3.508 & 3.516 & 3.596 & 3.52 & 3.618 \\
\hline
\end{tabular}

Table 9: Five BHW values of the produced filter samples

\begin{tabular}{|c|l|l|l|l|l|l|}
\hline \multirow{2}{*}{ Sample } & Reading & \multicolumn{2}{|l|}{ Brinell value (BHW) } & specimen 4 & specimen 5 \\
\hline \multirow{2}{*}{$\begin{array}{l}\text { Reading } \\
\text { number }\end{array}$} & specimen1 & specimen 2 & specimen 3 & & 53.10 & 56.11 \\
\cline { 2 - 7 } & 1 & 57.17 & 54.08 & 53.43 & 53.43 & 54.41 \\
\cline { 2 - 7 }
\end{tabular}




\begin{tabular}{|c|c|c|c|c|c|c|}
\hline & 3 & 55.42 & 53.75 & 53.75 & 52.78 & 56.46 \\
\hline & 4 & 57.53 & 53.10 & 52.47 & 54.41 & 55.77 \\
\hline & 5 & 56.11 & 54.41 & 53.75 & 54.08 & 55.42 \\
\hline & Average & 56.53 & 54.15 & 53.3 & 53.56 & 55.63 \\
\hline \multirow{7}{*}{ 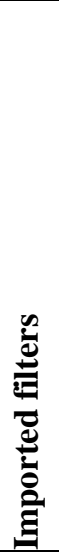 } & $\begin{array}{l}\text { Reading } \\
\text { number }\end{array}$ & specimen1 & specimen 2 & specimen 3 & specimen 4 & specimen 5 \\
\hline & 1 & 55.42 & 51.48 & 56.46 & 57.17 & 57.53 \\
\hline & 2 & 53.43 & 52.78 & 55.42 & 56.11 & 57.90 \\
\hline & 3 & 53.75 & 53.75 & 56.11 & 55.08 & 55.77 \\
\hline & 4 & 54.41 & 53.10 & 55.42 & 54.47 & 57.17 \\
\hline & 5 & 53.10 & 53.75 & 55.77 & 55.77 & 55.42 \\
\hline & Average & 54.02 & 52.97 & 55.83 & 55.72 & 56.75 \\
\hline \multirow{7}{*}{ 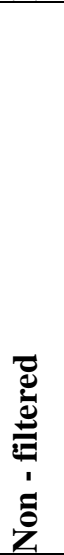 } & $\begin{array}{l}\text { Reading } \\
\text { number }\end{array}$ & specimen1 & specimen 2 & specimen 3 & specimen 4 & specimen 5 \\
\hline & 1 & 49.44 & 49.15 & 49.15 & 51.22 & 46.13 \\
\hline & 2 & 50.92 & 49.44 & 47.20 & 49.15 & 46.93 \\
\hline & 3 & 50.03 & 50.92 & 48.02 & 48.58 & 47.74 \\
\hline & 4 & 51.53 & 50.02 & 46.93 & 50.92 & 46.93 \\
\hline & 5 & 48.58 & 49.73 & 46.66 & 48.87 & 47.20 \\
\hline & Average & 50.1 & 49.85 & 47.59 & 49.74 & 46.98 \\
\hline
\end{tabular}

Brinell Hardness Test

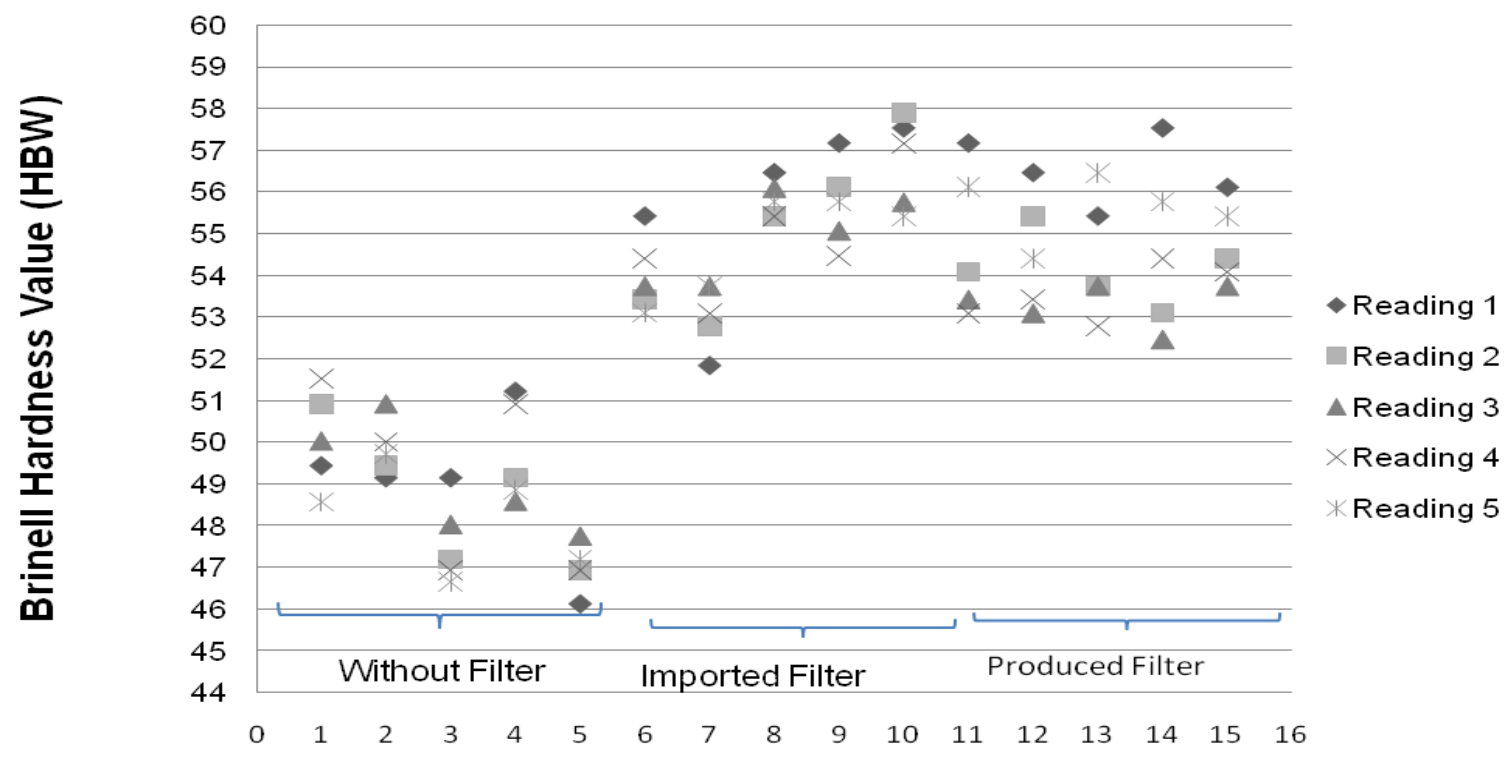

Fig.12 Comparison Brinell hardness value of produced and imported filtered with non-filtered samples 
As indicated in Figure 13 and 14, the results for surface inspection of filtered and non-filtered samples exposed, crack and porosity is clearly visible in the non-filtered samples.

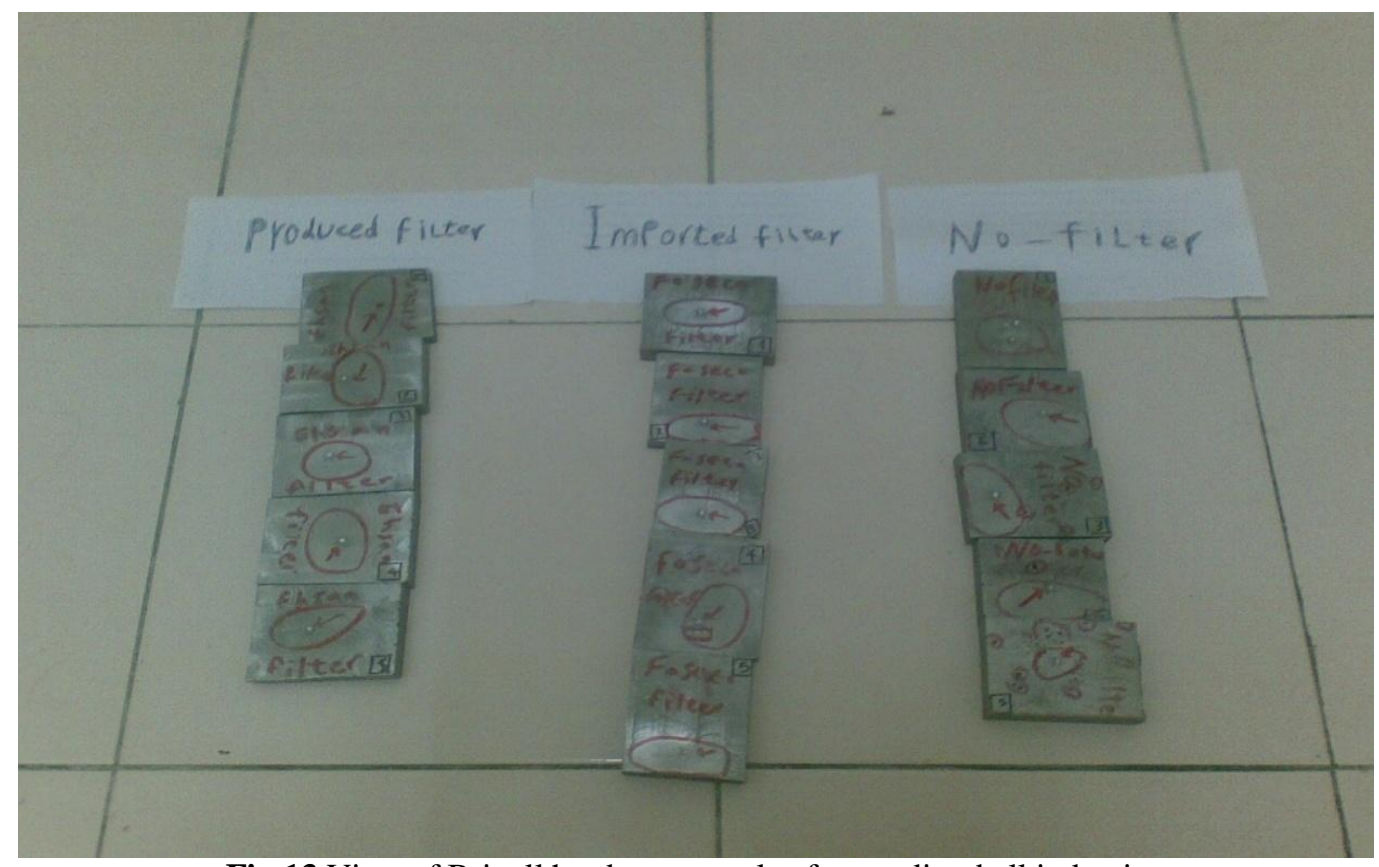

Fig.13. View of Brinell hardness sample after reading ball indention

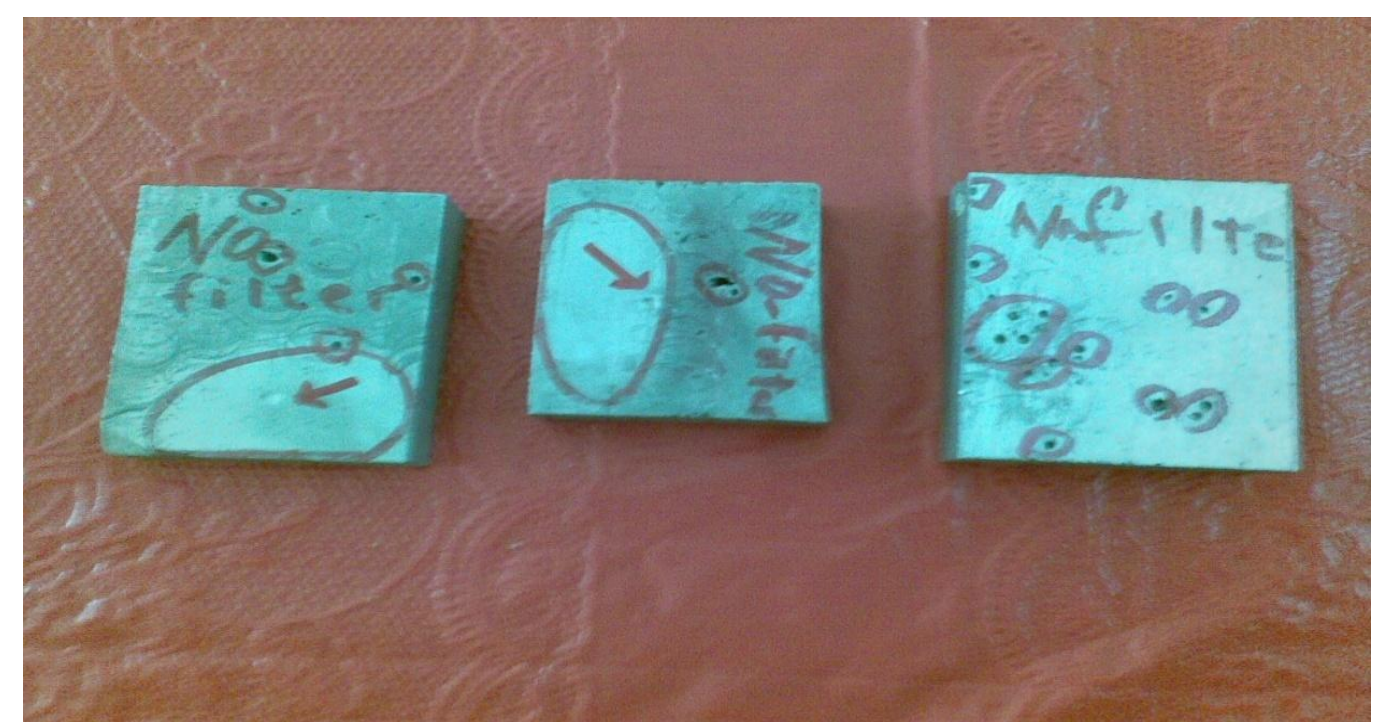

Fig.14.View of Brinell hardness sample after reading ball indention Porosity in non-filtered samples

\section{CONCLUSION}

According to objectives of present research the conclusion of this study is divided to two major sections. The fist section discusses on the important achievement for fabrication of ceramic foam filters and the second section explains the conclusions of efficiency of filtration technique on casting quality.

(a) Following conclusions are derived from the experimental results in fabrication of ceramic foam filters:

1. The filter of the present innovation is :

- Economical to produce

- Can be made in any shape and size
- Has excellent thermal shock resistance

- Acceptable permeability properties

- Resistant to chemical attack by molten aluminum alloys

2. Requirements for refractory filter materials for aluminum sand casting application were reviewed along with high temperature properties of candidate materials. The best combination of high thermal shock resistance is obtained by aluminum oxide $\left(\mathrm{AL}_{2} \mathrm{O}_{3}\right)$.

3. The manufacturing process is supposed to be carefully controlled to minimize wasting the raw materials. The excess slurry cannot be recycled. 
4. Aqueous slurry included water and sodium silicate should be mixed in correct amount with ceramic powder to prevent sticky or soft filter.

5. Low temperatures and short durations of baking ceramic slurry and burning out the sponge will improve the manufacturing economics. But sufficient time and temperature must be provided to achieve the desired strength and corrosion resistance properties of the final product.

(b) The key conclusion of efficiency of filtration technique on casting quality in present research is:

1. From experimental results, it is obviously clear that the insertion of a ceramic foam filter in the gating system will consistently prevent foreign material inclusions from entering the casting. Figure 14 shows that, ceramic foam filter is a convenient, cheap and efficient way to decrease casting surface defects.

2. The hardness value for aluminum LM6 alloy which is fabricated by sand casting, increased when ceramic foam filter is inserted into the gating system. The highest Brinell hardness (mean value) is 55.05 HBW for filtered samples and the lowest is 48.85 HBW for non-filtered samples. This value shows that hardness of samples which are filtered by ceramic foam filter is increased by $11.26 \%$ in comparison with non-filtered samples.

\section{ACKNOWLEDGEMENTS}

Authors would like to thank the UPM laboratory technician for their help in this experiment and specially thank to department of Mechanical and Manufacturing Engineering, Aerospace Engineering, Chemical and Environmental Engineering staff. A sincere gratitude is also extended to staff of Fars Iran Limited, Sales Manager Mr Mohammad Reza Yas and Commercial Manager Mr Alireza Mojaver to their assistance in preparation Foseco Ceramic Foam Filter and also Raw materials included polyurethane foam and refractory powders.

\section{REFERENCES}

[1] Alquist, 2003 B.R. Alquist, Flow Modification Properties of Ceramic Foam Filters - A Summary of Recent Work, Foseco Foundry Practice, No.238, ( 2003).

[2] Brockmeyer, 1982 W.J. Brockmeyer, Ceramic foam filters, (1982) US Patent No. 4343704.

[3] Corns, 1991 D.D. Corns, Metal filtration: a positive means to clean castings, The Foundry man Handbook, (1991) pp. 370-372.

[4] Feng, 2007 Ch. Feng, Low Expansion Corrosion Resistant Ceramic Foam Filter for Molten Aluminum Filtration, (2007) US Patent No. WO/2007/120483

[5] Foseco Metallurgical Inc, 1990 MSDS REV. No. 1, Doc.Ref No.822708, Sivex 200S, (1990)

[6] Foseco Metallurgical Inc, 1997 MSDS REV. No. 4, Sivex S, (1997)

[7] Foseco Metallurgical Inc, 2007 Doc.Ref No. 506443, Sivex FC, (2007)
[8] Goods and Neuschwanger, 1999 S.H. Goods and C. L. Neuschwanger, Mechanical properties of particlestrengthened polyurethane foam, Journal of Applied Polymer Science74 (11) (1999) pp. 2724-2736.

[9] Hebner, 1995 P.W. Hebner, Polyurethane Foam: Polymers' Cinderella Product, Insight 95 International Conference, (1995).

[10] Jerry and Aubrey, 1989 W. Jerry and L.S. Aubrey, Ceramic foam filter and process for preparing same, (1989) US Patent No. 4885263.

[11] Jerry, 1983 W. Jerry, Ceramic foam filter and aqueous slurry for making same, (1983) US Patent No. 4391918.

[12] Joseph, 1990 K.P. Joseph, Polyurethane foam, (1990) US Patent No. 4939184

[13] Kinikoglu, 1998 N.G. Kinikoglu, Ceramic Foam Filter Production, (1998), US Patent No. WO1998048918.

[14] Millin, 1999 T.M. Millin, Optimize Casting Design and Quality with Process Simulation, Engineered Casting solutions, (1999).

[15] Monroe, 1992 R.W. Monoroe, Expendable pattern casting American Foundrymen's Society, (1992) pp.21-37

[16] Pryor and Thomas, 1976 J.M. Pryor and J.G. Thomas, Ceramic foam filter, (1976) US Patent No. 3947363.

[17] Qutten, 1996 J. Outten, KALPUR for steel Direct Pouring System Improves Yield, Productivity and Quality, Foundry Practice, No.227, (1996).

[18] Sandford and Sibley, 1996 P. Sandford, and S.R. Sibley, The application of foam filters to optimize aluminum casting production, Foseco Foundry Practice, No.227, (1996).

[19] Sadon et al., 2001 P. Sadon, D. Hurdebourc, J. Morisse and K. Tylor, Industrial experience in the filtration of cast iron at the Peugeot Citroen Foundries, Proceedings of Conaf $2001,10^{\text {th }}$ Foundry Congress, Sao Paulo, Brazil, May 23-25 (2001).

[20] Schmahl and Aubrey, 1993a J.R. Schmahl and L.S Aubery, Application of advanced reticulated ceramic foam filter technology to produce clean steel castings, AFS Transaction, (1993), pp.58-66.

[21] Schmahl and Aubrey, 1993b J.R. Schmahl and L.S Aubery, Filtration with Reticulated Silicon Carbide Foam. An Effected Means for Inclusion Removal in Cray and Nodular Iron Casting, SELEE Corporation, Hendersonville, North California, AFS Transactions, (1993), pp. 1011-1018.

[22] Sousa and Rambo, 2008 E.D. Sousa and C.R. Rambo, Microstructure and properties of LZSA glass-ceramic foams Materials Science and Engineering476 (1-2) (2008) pp. 89-97.

[23] Taslicukur et al., 2007 Z. Taslicukur, C. Balaban and N. Kuskonmaz, Production of ceramic foam filters for molten metal filtration using expanded polystyrene Journal of the European Ceramic Society 27 (2-3) (2007), pp. 637-640.

[24] Wenping, 2006 L. Wenping, Comparison of Different Filter Aid Permeability Test Methods, American Filtration \& Separations Society Spring Conference, Donald E. (2006). 